\title{
Professional opinion on the question of changes in autism incidence
}

\author{
M. Catherine DeSoto", Robert T. Hitlan \\ University of Northern Iowa, Cedar Falls, USA \\ Email: *cathy.desoto@uni.edu
}

Received 8 January 2013; revised 13 February 2013; accepted 21 February 2013

Copyright (C) 2013 M. Catherine DeSoto, Robert T. Hitlan. This is an open access article distributed under the Creative Commons Attribution License, which permits unrestricted use, distribution, and reproduction in any medium, provided the original work is properly cited.

\begin{abstract}
The question of whether the prevalence increase observed in autism due to an actual increase in the incidence of autism is a matter of concern to professional psychologists, and has been a matter of debate. As professionals trained in diagnosis and research methodology, the opinions of psychologists are of interest. We report the results of what we believe to be the first survey of professional opinion on the topic. Results suggest that among professional psychologists with a terminal degree $(n=88)$, the majority believe that diagnostic changes can not fully account for the observed increase; $72 \%$ reported either the true rate may have, or definitely has, increased. In this sample, the professionals who are certain about the occurrence of a real increase $(n=20)$ are five times as many as those who do not think the increase has occurred $(n=4)$. These results are not meant to document whether or not an increase has or has not occurred, but instead speak to the question of consensus opinion among professional psychologists. What experts believe is an empirical question, and statements about what experts believe should be empirically based.
\end{abstract}

Keywords: Counselor Attitudes; Professional Opinion; ASD; Autism Prevalence; Autism

\section{INTRODUCTION}

A little more than a single generation ago, about one in every 2000 children were classified as autistic; today, the rate is approximately 13 per every 2000 children [1]. At least some portion of this increase is considered to be a result of diagnostic changes $[2,3]$. On the other hand, increases in autism and autism spectrum disorders (ASD)

\footnotetext{
${ }^{*}$ Corresponding author.
}

have been reported in numerous parts of the world [4-6] and - most importantly - continuing increases have now been carefully documented well after formal changes in diagnosis occurred. This is true using standardized definition and ascertainment methods [1].

The question of whether some or all of the increase in autism prevalence is due to diagnostic changes has led to a contentious debate within the autism research community. Perhaps the reason the debate has gotten intense is that an actual increase has rather profound implications: if the true incidence is currently increasing, or has recently increased, then presumably something environmental is causing it. Autism has a strong genetic component. High heritability estimates have been reported, although more recent studies find shared environment is accounting for more of the variance. Hallmayer and colleagues [7] found moderate heritability of 0.37 , with a larger amount of variance related to shared environment effects. In any case, gene pools do not change this fast: there is no way that a ten-fold, five-fold, or even a doubling across the span of a single generation could be due to a change in the gene pool. Mutations and natural selection do not work that quickly. If an actual change in prevalence happens over the course of one generation, the answer has to lie elsewhere, such as macro level environmental changes interacting with individual level genetics [8].

To begin, we wish to make clear that there is overwhelming evidence for changes in diagnostic practice regarding autism. We are not aware of anyone who has ever made a claim that diagnostic changes have not occurred. It is obvious that many children receiving an ASD diagnosis today would not have been diagnosed as having archetypal autism either currently or decades ago. Professional understanding of ASD has evolved from a yes-or-no diagnosis to a spectrum of severity: this is not in dispute and never has been. The question is whether 
the total number of cases has increased, or-possibly—if there are more severely disabled children.

We agree that the body of research as it existed a decade ago left open the possibility that there may have been no increase in the actual incidence of autism. But we believe that multiple recent studies (reviewed below) are convergent evidence for an actual increase across several countries. A decade ago, in 2003, we did not disagree with Eric Fombonne when he wrote:

"Whereas evidence suggests that a substantial part of the increase in prevalence is due to methodological factors, the additional possibility of a secular increase can not be ruled out. Unfortunately, most available epidemiological data (were) derived from surveys, and the few studies that provide incidence rates have not been adequate to test the hypothesis. In addition, no strong environmental exposures have been identified" (p. 88) [2].

However, things have changed in the past ten years.

First, the importance of environmental exposures has been well-demonstrated by multiple independent lab groups, using varied research methodology (see Table 1). This offers substantial evidence for environmental exposures playing a key role in autism etiology. Further, pockets of high prevalence may be of interest. Variations in school district autism prevalence have been studied and found not to be random, but have been shown to predictable as a function of the amount of, and distance to, toxic sources; this has been demonstrated by two independent lab groups $[9,10]$. In the past decade, longitudinal studies that follow infants across time have shown that exposure to toxins during pregnancy or early infancy predicts later ASD symptoms [11]. It should also be recognized that low levels of neurotoxins such as mercury (levels that $8 \%$ of American women have in their blood streams) cause specific damage to developing human brain cells [12]. It is important to realize that lack of noticeable effects in a pregnant mother is not assurance of lack of damage to an unborn child; due to the nature of the placental barrier, the level of some heavy metals in the unborn child may be as much as $70 \%$ higher than the mother's circulating supply $[13,14]$ further increasing the plausibility of such toxins as an environmental candidate. Ironically, the single study that Fombonne cited back in 2003 that directly tested blood levels of the heavy metal mercury among autistic children and control subjects failing to find higher mercury levels among those with autism was subsequently found to contain math errors [15], and has since had an Erratum published. Correct analysis of the data set demonstrated a significant relationship in the sample [16-18]. Although perhaps an open question a decade or more ago, a role for environmental contaminants, broadly defined, should now be recognized in autism etiology.

Atladottir et al. [6] reported the change in autism for children born in Denmark between the years 1990 to 1999. It is crucial to note that Atladottir et al. used standardized case ascertainment and standardized diagnostic procedures to document an increase in both Autism Spectrum Disorders (ASD) and Childhood Autism in Denmark. The full cohort was used $(n=669,995)$. The increase was separately measured for ASD (broader definition) and Childhood Autism (stricter definition) - and the increase was most pronounced when the stricter diagnostic definition of Childhood Autism was used. This was not survey data, it was total incidence measured the same way across time in a defined location. It meets any criteria for careful assessment for proper measure of incidence change.

But there are some studies that apparently do not show an increase. These should be considered carefully. Latif and Williams [19] in their research report that Kanner's Autism has not increased. Kanner's autism refers to the "classic" autism as defined by Leo Kanner. The reported lack of increase in Kanner's Autism is based on approximately two children per year being classified as "other forms of autism" instead of Kanner's. Moreover, the "drop in Kanner's autism" was occurring in the broader context of a dramatic increase in total "autism" cases across the years of study. This small study is not strong evidence against an increase in autism, and could be seen as evidence for an increase in neurodevelopmental disorders, broadly defined.

One route that has not been employed to determine if an increase in incidence has occurred is to poll experts who have worked with autistic individuals across time and/or have training in clinical research methodology. To our knowledge, this is the first report of a systematic survey of experts on the matter, although both sides have claimed knowledge of professional opinion: "Though the concept of an 'autism epidemic' has become a notion of

Table 1. Autism prevalence and neurotoxins: replicated findings.

\begin{tabular}{lll}
\hline $\begin{array}{l}\text { Biomarker studies showing higher levels } \\
\text { of toxins among persons with ASD }\end{array}$ & $\begin{array}{l}\text { ASD high-prevalence pockets } \\
\text { (within-study) }\end{array}$ & $\begin{array}{l}\text { Increased rates associated } \\
\text { with sources of contaminants }\end{array}$ \\
\hline Edelson, 2000 [22] & Hoshino et al., 1982 [25] & Windham et al., 2006 [29] \\
Nataf et al., 2006 [23] & Oliviera et al., 2007 [26] & Roberts et al., 2007 [30] \\
Eskanazi et al., 2007 [11] & Kamer et al., 2004 [27] & Palmer et al, 2008 [9] \\
Geier \& Geier, 2006 [24] & Barnevik-Olsson, Gillberg \& Fernell, 2008 [28] & DeSoto, 2009 [10] \\
DeSoto \& Hitlan, 2007 [16] & & Volk et al., 2011 [31] \\
& & DeSoto \& Hitlan, 2012 [32] \\
\hline
\end{tabular}


faith among parent campaigners, most authorities in the field believe that the increased prevalence of autism can be readily explained by widening diagnostic categories and increased professional and public awareness" (p. 297, Fitzpatrick, 2007) [20]. This is an empirical investigation of such assertions, which are sometimes stated without support. Specifically, we hypothesized that clinical experts would not dismiss the increase in autism as artifact caused by increased awareness.

\section{METHODS}

\subsection{Participants}

Ninety-one professionals agreed to participate in the survey. Participants who were contacted but did not meet criteria were not included (three respondents reported not holding a terminal degree). Of the 88 remaining participants, 29 were clinical psychologists contacted through their university affiliation, 59 were contacted via their private practice. Of those contacted via private practice office, $9 \%$ were practicing in a small town or rural area, $47 \%$ were practicing in a medium sized city, and $44 \%$ were practicing in a large city or urban area.

Participants' time since obtaining their degree ranged from three to 41 years with a mean of $22.3(\mathrm{SD}=9.97)$ years (one participant had both a $\mathrm{PhD}$ and an $\mathrm{MD}$ and the date of the first degree was used). The majority held a PhD (84\%), with a minority holding a PsyD (8\%), an $\operatorname{EdD}(5 \%)$, an MD (2\%), or both a PhD and an MD (1\%). In terms of professional activities, $67 \%$ had provided services to autistic persons at some point in their professional careers; $40 \%$ of participants had published in a peer-reviewed outlet in the past five years.

\subsection{Procedures}

All procedures were reviewed and approved by the University of Northern Iowa IRB and those conducting the survey completed IRB training. The design was a stratified random sample with participants selected from large, medium and small cities across the United States and various regions. Specifically, participants $(\mathrm{n}=88)$ came from the following states: Arizona (1), California (13), Florida (15), Iowa (11), Kansas (5), Mississippi (1), Montana (1), New York (9), Oregon (11), Texas (12), and Virginia (9). To ensure anonymity, only the state and the city size were coded. Persons holding a doctorate (MD, $\mathrm{PhD}$, PsyD, EdD) were contacted by phone and asked to complete a short survey on Autism prevalence. Participants were told the survey was on the topic of expert perception on autism and that it would take less than 90 seconds to complete. Very few psychologists who answered the phone refused to participate in the short sur- vey, with a response rate of over $90 \%$ (although it should be noted that often calls went unanswered, or a voice mail was encountered). Potential subjects were randomly selected from on-line phone book listings

(yellowpages.com), or from clinical psychology faculty listings at a university.

\subsection{Measures}

Participants were asked, "In your opinion, which is most accurate about the changing rate of autism?" Par- ticipants selected from five responses: A. I am very cer- tain that the true rate of autism has NOT increased at all; B. I doubt the true rate of autism has increased at all; C. I think the true rate of autism may have actually increased some; D. The actual rate of autism has definitely increased; E. I have no opinion or can't say. Participants were also asked to respond in a Yes/No fashion to the specific question of whether the increase in autism was fully explainable by changes in how autism is diagnosed.

\section{RESULTS}

Six percent of respondents reported they had not heard anything about the possibility of a change in the prevalence of autism, while 94\% reported they were aware of the issue.

Of the five participants who were not aware of the increase in ASD diagnoses, four reported they had no opinion as to whether or not the true rate of autism has increased. The results are displayed in Figure 1. Of those who reported an opinion $(\mathrm{n}=75), 72 \%$ reported either the true rate may have or definitely has increased. In this sample, five times more professionals think a real increase has definitely occurred $(n=20)$ than think a real increase has not occurred $(n=4)$.

Results showed no relationship between response and years since degree was obtained, $r(73)=0.02$, ns, nor did a history of having provided services to autistic individuals predict response on this question, the point biserial correlation was $\Phi(75)=0.15$, ns. Choosing response A or B indicated a belief towards a real increase having occurred, while a $\mathrm{C}$ or $\mathrm{D}$ response leaned towards no increase. Grouping participants this way still indicated no systematic difference between participants who chose choice A or B (real increase) to those who chose C or D (no increase) in terms of years since degree was obtained, $\mathrm{t}(73)=0.11$, ns; however, there was a significant difference regarding history of having worked with autistic clients, $\Phi(75)=0.20, \mathrm{p}=0.04)$ on this question, such that having provided service was associated with a greater tendency to reject the idea of a real increase.

Participants were also asked to respond to the specific question of whether the increase in autism was fully explainable by changes in how autism is diagnosed. Re- 
sponses are depicted in Figure 2. Twenty-eight percent of professionals surveyed thought that diagnostic changes were accounting for all of the increase in diagnoses, while $60 \%$ thought this did not fully explain the increase.

To determine if history of providing service related to the belief that the increase in autism was explained by diagnostic changes, the responses were correlated with a history of providing service to those with ASD using the point-biserial correlation. Again, history of providing service related to the tendency to believe the change in ASD prevalence was not fully explainable by changes in diagnostic criteria, $\Phi(75)=0.24, p=0.04$. The tendency for participants to believe that the increase in ASD is not fully due to diagnostic issues was larger for the group who did not provide direct service to those with ASD (see Figure 3). Nonetheless, as Figure 3 depicts, the ma-

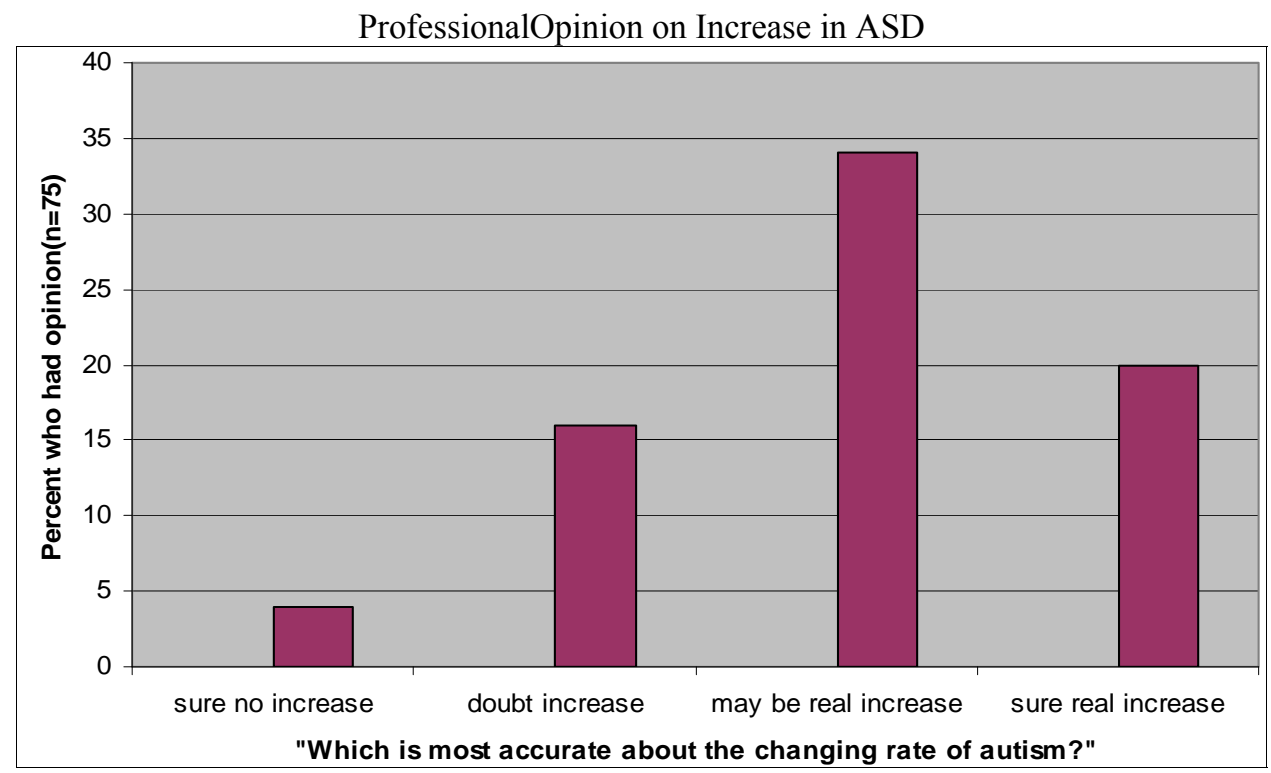

Figure 1. Professional responses regarding the increase in autism prevalence; "I am very certain that the true rate of autism has NOT increased at all," "I doubt the true rate of autism has increased at all," "I think the true rate of autism may have actually increased some," or "The actual rate of autism has definitely increased."

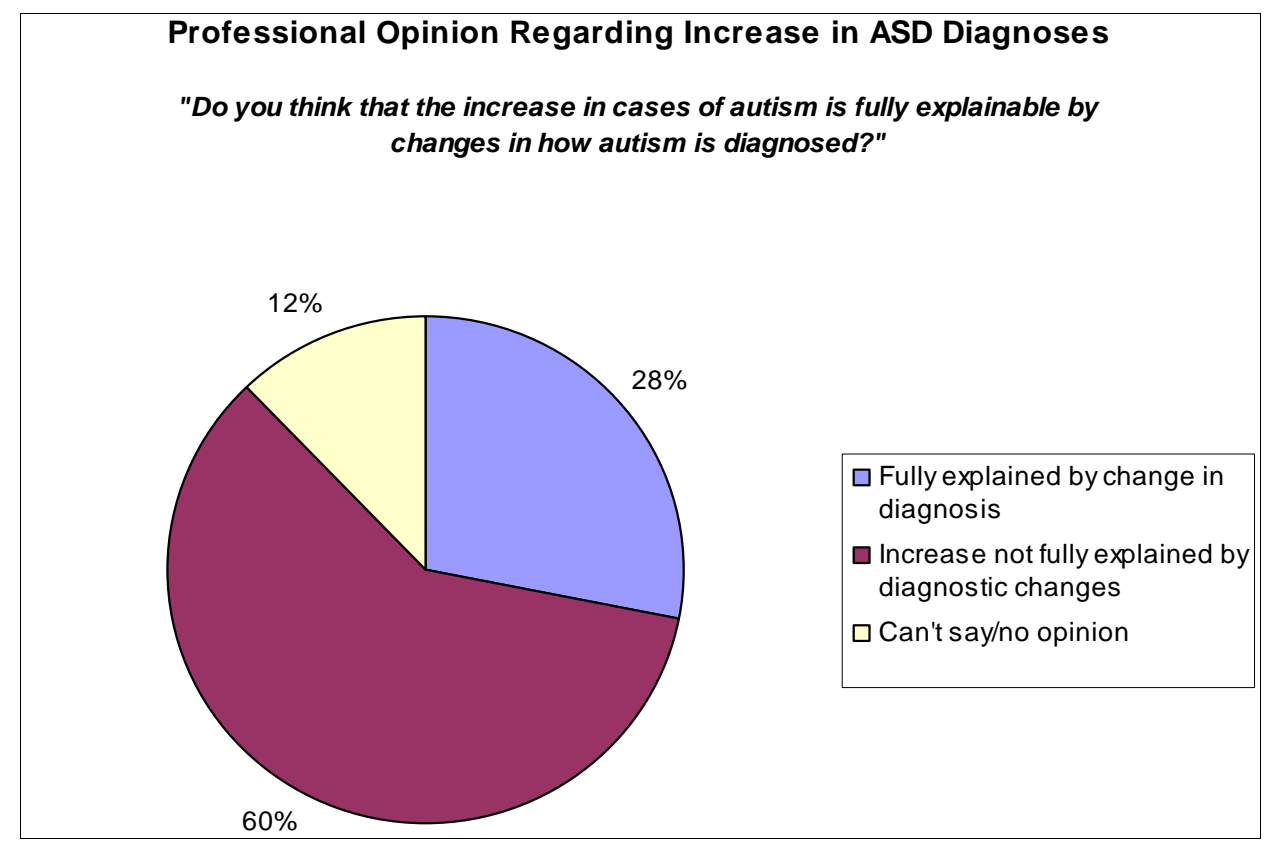

Figure 2. The majority of professionals state they believe the increase in autism cases is not fully explainable by changes in how autism is diagnosed. 


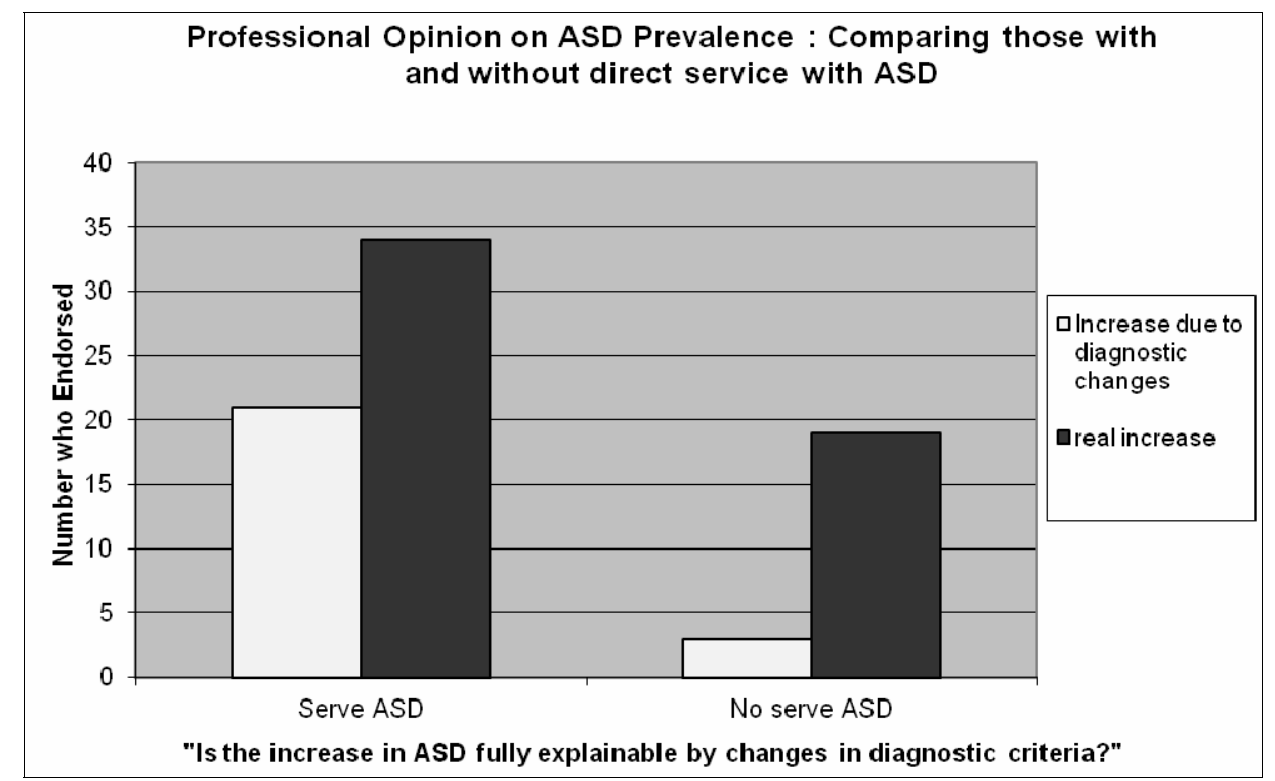

Figure 3. Professional responses as a function of having or not having provided services to autistic persons. Participants were asked to answer Yes or No the question, "Do you think that the increase in cases of autism is fully explainable by changes in how autism is diagnosed?"

jority of professionals state they believe the increase in autism cases is not fully explainable by changes in how autism is diagnosed; this is true both for those with, and without, a history of providing professional service to those with ASD

\section{DISCUSSION}

We have reported the results of a survey of professional opinion on the topic of increased autism prevalence. The results indicate that the majority of professionals do not believe that the increase in reported autism is fully explainable by changes in diagnostic practice. Twenty-eight percent of professionals surveyed thought that diagnostic changes were accounting for all of the increase in diagnoses, while $60 \%$ thought this did not fully explain the observed increase.

It should be noted that this survey did not measure opinion on whether a change in diagnostic practice has occurred. The fact that diagnostic changes have occurred is well known and we expect that professionals are aware of this; nonetheless future research on professional opinion might address this question as well. Similarly, the purpose of the survey was not to gauge what percentage of the change in autism might be due to diagnostic changes, but to conduct a survey to determine if practicing professionals believe that all of the increase in prevalence rates is due to changes in diagnostic practice.

In planning the study, we were cognizant of the tendency for those who feel strongly about a subject to be more likely to respond and the potential for this type of response bias to fatally flaw surveys [21]. Future studies on professional opinion must find ways to guard against this. Our response rate was achieved by calling randomly selected numbers until an actual person answered. Originally we left messages on answering machines, but after leaving 25 messages and getting no return calls, we decided to stop leaving messages. It should be noted that after we stopped leaving messages, one message was returned. This person was adamant that no real increase had occurred. This response was included in the analysis, but was somewhat of an outlier in terms of response. We include this to caution other researchers that for this topic, the issue of response bias is important to consider. This topic is one that engenders strong beliefs among some; any survey design that allows participants to self-select for inclusion in the sample (such as leaving phone messages and inviting a return call) may result in a biased sample.

Professional opinion on autism prevalence is important to consider. Public opinion as well as reports in popular media are likely to be swayed by exaggeration, weak research, poorly understood research or strongly worded commentary. Although professionals are not immune to sensationalism, those with a terminal degree have advanced research training, clinical skills and firsthand experience with diagnostic issues. Thus, they may be more able to consider data more objectively or evaluate genuine trends more accurately.

\section{REFERENCES}

[1] Centers for Disease Control Autism and Developmental 
Disabilities Monitoring Network (2009) Prevalence of autism spectrum disorders-Autism and developmental disabilities monitoring network, United States, 2006. Morbidity and Mortality Weekly Report, 58, SS-10.

[2] Fombonne, E. (2003) The prevalence of autism. Journal of the American Medical Association, 289, 87-89. doi:10.1001/jama.289.1.87

[3] Wazana, A., Breshnahan, M. and Kline, J. (2007) The autism epidemic: Fact or artifact? Journal of the American Academy of Child and Adolescent Psychiatry, 46, 721-730. doi:10.1097/chi.0b013e31804a7f3b

[4] Merrick, J., Kandel, I. and Morad, M. (2004) Trends in autism. International Journal of Adolescent Medicine and Health, 16, 75-78. doi:10.1515/IJAMH.2004.16.1.75

[5] Gillberg, C., Cederlund, M., Lamberg, K. and Zeijlon, L. (2006) The autism epidemic: The registered prevalence of autism in a Swedish urban area. Journal of Autism and Developmental Disorders, 36, 429-435. doi:10.1007/s10803-006-0081-6

[6] Atladottir, H.O., Schendel, D., Dalsgaard, S., Thomsen, P.H. and Thorsen, P. (2007) Time trends in reported diagnoses of childhood neuropsychiatric disorders: A Danish cohort study. Archives of Pediatrics and Adolescent Medicine, 161, 193-199. doi:10.1001/archpedi.161.2.193

[7] Hallmayer, J. et al. (2011) Genetic heritability and shared environmental factors among twin pairs with autism. Archives of General Psychiatry, 68, 1095-1102. doi:10.1001/archgenpsychiatry.2011.76

[8] Lawler, C.P., Croen, L.A., Grether, J.K. and Van de Water, J. (2004) Identifying environmental contributions to autism: Provocative clue and false leads. Mental Retardation and Developmental Disabilities Research Review, 10, 292-302. doi: $10.1002 / \mathrm{mrdd} .20043$

[9] Palmer, R., Wood, S. and Blanchard, R. (2008) Proximity to point sources of environmental mercury release as a predictor of autism. Health Place, 15, 18-24. doi:10.1016/j.healthplace.2008.02.001

[10] DeSoto, M.C. (2009) Ockham's razor and autism: The case for developmental neurotoxins contributing to a disease of neurodevelopment. Neurotoxicology, 30, 331-337. doi:10.1016/j.neuro.2009.03.003

[11] Eskanzi, B., Marks, A.R., Bradman, A., Harley, K., Barr, D.B., Johnson, C., et al. (2007) Organophosphate pesticide exposure and neurodevelopment in young MexicanAmerican children. Environmental Health Perspectives, 115, 792-798. doi:10.1289/ehp.9828

[12] Tamm, C., Duckworth, J., Hermanson, O. and Ceccatelli S. (2006) High susceptibility of neural stem cells to methylmercury toxicity: Effects on cell survival and neuronal differentiation. Journal of Neurochemistry, 97, 6978. doi:10.1111/j.1471-4159.2006.03718.x

[13] Stern, A.H. and Smith, A.E. (2003) An assessment of the cord blood: Maternal blood methylmercury ratio: Implications for risk assessment. Environmental Health Perspectives, 111, 1465-1470. doi:10.1289/ehp.6187

[14] Morissette, J., Takser, L., St-Amour, G., Smargiassi, A., Lafond, J. and Mergier, D. (2004) Temporal variation of blood and hair mercury levels in pregnancy in relation to fish consumption history in a population living along the St. Lawrence River. Environmental Research, 95, 263274. doi:10.1016/j.envres.2003.12.007

[15] Ip, P., Wong, V., Ho, M., Lee, J. and Wong, W. (2004) Mercury exposure in children with autistic spectrum disorder: Case-control study. Journal of Child Neurology, 19, 431-434.

[16] DeSoto, M.C. (2008) A reply to Soden: Your data shows autistic children have higher levels of heavy metals. Clinical Toxicology, 46, 1098. doi:10.1080/15563650802314368

[17] Brumback, R. (2007) Note from editor-in-chief about erratum for Ip et al. article. Journal of Child Neurology, 22, 1321. doi: $10.1177 / 0883073807308149$

[18] DeSoto, M.C. and Hitlan, R.T. (2007) Blood levels of mercury are related to diagnosis of autism: A reanalysis of an important data set. Journal of Child Neurology, 22, 1308-1311. doi: $10.1177 / 0883073807307111$

[19] Latif, A.H.A. and Williams, W.R. (2007) Diagnostic trends in autistic spectrum disorder in South Wales valleys. Autism, 11, 479-487. doi: $10.1177 / 1362361307083256$

[20] Fitzgerald, M. (2007) Autism and environmental toxicity. Lancet Neurology, 6, 297. doi:10.1016/S1474-4422(07)70066-2

[21] Babbie, E. (2007) The practice of social research. 11th Edition, Thompson Wadsworth, Belmont.

[22] Edelson, S.B. and Cantor, D. (2000) The neurotoxic etiology of the autistic spectrum disorders: A replication study. Toxicology and Industrial Health, 16, 239-247.

[23] Nataf, R., Skorupka, C., Amet, L., Lam, A., Springbett, A. and Lathe, R. (2006) Porphyrinuria in childhood autistic disorder: Implications for environmental toxicity. Toxicology and Applied Pharmacology, 214, 99-108. doi:10.1016/j.taap.2006.04.008

[24] Geier, D.A. and Geier, M.R. (2006) A prospective assessment of porphyrins in autistic disorders: A potential marker for heavy metal exposure. Neurotoxicology Research, 10, 57-64. doi:10.1007/BF03033334

[25] Hoshino, Y., Tachibna, Y., Watanabe, H., Kumashiro, R. and Yashima, M. (1982) The epidemiological study of autism Fukushima-Ken. Folia Psychiatric Neurology Japan, 36, 115-124.

[26] Oliveira, G., Ataíde, A., Marques, C., Miguel, T.S., Coutinho, A.M., Mota-Vieira, L., Gonçalves, E., Lopes, N.M., Rodrigues, V., Carmona da Mota, H. and Vicente, A.M. (2007) Epidemiology of autism spectrum disorder in Portugal: Prevalence, clinical characterization, and medical conditions. Developmental Medicine and Child Neurology, 10, 726-733. doi:10.1111/j.1469-8749.2007.00726.X

[27] Kamer, A., Diamond, R., Inbar, Y., Zohar, G.W., Youngmann, D. and Senecky, A.H. (2004) A prevalence estimate of pervasive delopmental disorder among immigrants to Israel and Israel natives-A file review study. Social Psychiatry and Psychiatric Epidemiology, 39, 141-145. doi:10.1007/s00127-004-0696-X

[28] Barnevik-Olsson, M., Gillberg, C. and Fernell, E. (2008) Prevalence of autism in children born to Somali parents 
living in Sweden: A brief report. Developmental Medicine and Child Neurology, 50, 598-601. doi:10.1111/j.1469-8749.2008.03036.x

[29] Windham, G.C., Zhang, L., Gunier, R., Croen, L.A. and Grether, J.K. (2006) Autism spectrum disorders in relation to distribution of hazardous air pollutants in the San Francisco Bay Area. Environmental Health Perspectives, 114, 1438-1444. doi:10.1289/ehp.9120

[30] Roberts, E.M., English, P.B., Grether, J.K., Windham, G.C., Somberg, L. and Wolff, C. (2007) Maternal residence near agricultural pesticide applications and autism spectrum disorders among children in the California Cen- tral Valley. Environmental Health Perspectives, 115, 14821489

[31] Volk, H.E., Hertz-Picciotto, I., Delwiche, L., Lurmann, F. and McConnell, R. (2011) Residential proximity to freeways and autism in the CHARGE study. Environmental Health Perspecives, 119, 873-877. doi:10.1289/ehp. 1002835

[32] DeSoto, M.C. and Hitlan, R.T. (2012) Fish consumption advisories and the surprising relationship to prevalence rate of developmental disability as reported by public schools. Journal of Environmental Protection, 3, 15791589. doi:10.4236/jep.2012.311174 